Peer-Reviewed Article

ISSN: 2162-3104 Print/ ISSN: 2166-3750 Online

Volume 7 Number 1 (2017), pp. 136-153

(C) Journal of International Students

http://jistudents.org/

\title{
The Cultural Elements of Academic Honesty
}

\author{
LaNette W. Thompson \\ Baylor University, USA \\ Janet H. Bagby \\ Baylor University, USA \\ Tracey N. Sulak \\ Baylor University, USA \\ Janet Sheets \\ Baylor University, USA \\ Tonya M. Trepinski \\ Texas A\&M International University, USA
}

\begin{abstract}
We examined the impact of a workshop on Asian international graduate students' understanding of a U. S. American university's concept of academic honesty. The workshop, taught from a cultural perspective, explained the U.S. American university's expectations to 19 participants. Data was obtained from a workshop post-test and from subsequent interviews of three workshop participants who relayed their views of textual practices in their home countries. Sixty-seven graduate students from the general graduate student population completed the workshop post-test without benefit of the workshop. Trends in the data supported the workshop's effectiveness and pointed to the importance of helping international students understand their host university's expectations.
\end{abstract}

Keywords: Asian international students, graduate students, academic honesty workshop 
Students in higher education are becoming increasingly mobile. Worldwide, in 2000, approximately 2 million students were enrolled in institutions of higher education outside their own countries. That figure doubled to more than 4.5 million by 2012 (OECD, 2014). In the United States, for the 2013/2014 school year, approximately 886,000 international students enrolled in U. S. American schools. Of that number, more than 530,000 students came from Asian countries (Institute of International Education, 2015).

The growing enrollment of international students in the United States is receiving prominent attention as the media highlights the financial benefits of foreign students willing to pay out-of-state tuition to universities struggling with budget cuts (Lewin, 2012). Increasing international student populations on campus also foster concerns for the challenges of meeting their needs. Lipson (2008) advised international students intent on studying in the United States and Canada that other than English proficiency, the two issues international students face that affect their success in North American academics are understanding the freedom to express their own opinions in class and knowing what constitutes academic honesty at their host universities. For students from a society where individualism is frowned upon and students may study by copying information from experts, academic honesty as defined by a host institution may be a difficult concept to grasp (Gu, 2010; Kim, 2011; Leki, 2006; Liao \& Tseng, 2010; Sato \& Hodge, 2009; Shi, 2006).

Universities and institutions of higher learning differ in how they address plagiarism, who is responsible for enforcing policies, and which learning practices are considered academically dishonest (Gallant, 2008; Jamieson, 2008; Pecorari, 2008). International students may arrive in their host country with little knowledge of concepts or the unwritten practices of their new academic culture (Chen \& Van Ullen, 2011; Holmes, 2004). Though students may be familiar with the copyright laws of their own countries, they may not be familiar with the laws of their host country or the plagiarism policies of the university they are attending (Craig, Federici, \& Buehler, 2010). When international students come from an educational system where they are expected to quote their teacher's opinions or where knowledge content has received more emphasis than knowledge delivery, complications may arise (Gu, 2010; Song-Turner, 2008). If international students have had limited experience writing in English, they may need special help to avoid plagiarism and its consequences (Amsberry, 2010a; Chen \& Van Ullen, 2011; Pecorari, 2008).

This study began from a desire to provide the Asian graduate participants an opportunity to increase their knowledge of their host university's concept of academic honesty since graduate students are not required to complete an academic integrity tutorial at the research site. By 
assessing the influence of an academic honesty workshop that was taught from a cultural perspective, this study responded to a gap in the literature concerning the benefits of cultural workshops in helping Asian international students understand their host university's concept of academic honesty. This study also contributed to our knowledge concerning the importance of helping international students understand their host university's expectations.

\section{LITERATURE REVIEW}

According to the Merriam-Webster (2015) dictionary, the word "plagiarism" means "the act of using another person's work or ideas without giving credit to that person." The Oxford (2016) dictionary includes two acts in its definition of plagiarism, not only taking the words or ideas of another, but also "passing them off as one's own." This latter definition points out a conflict in the use of the term "plagiarism" to refer to all incidents of textual borrowing. Some authors are questioning the use of one term to describe those who intend to deceive and those who are simply unfamiliar with acceptable writing practices (Amsberry, 2010b; Holmes, 2004; Pecorari, 2008).

In a study examining plagiarism policies, Pfeuffer-Scherer (2010) noted that all of the universities studied had posted plagiarism policies on their websites, but the universities differed as to where the information was located. Some universities included plagiarism information in the academic conduct code whereas some listed it within student affairs policies. Although the universities that were studied generally agreed on definitions, they differed in how infractions were treated. Within a university, acceptable learning practices may differ from department to department. It may be assumed that students will collaborate in the math department, for example, but collaboration in other departments such as the humanities is considered academically dishonest (Gallant, 2008). International students must therefore understand each discipline's practices since acceptable learning practices may differ from department to department (Day, 2008; Hu \& Lei, 2012).

Universities throughout the world also differ in how they educate their students on academic honesty topics. After studying graduate students' understanding of plagiarism at universities in Pakistan, Ramzan, Munir, Siddique, and Asif (2012) called for universities to publish their academic honesty policies as well as hold workshops and seminars to help students better understand the concept of plagiarism.

Multiple researchers have stressed the importance of helping international students understand their host university's academic policies and concept of plagiarism (Abasi, Akbari, \& Graves, 2006; Abasi \& Graves, 2008; Amsberry, 2010a; Chen \& Van Ullen, 2011; Duff, Rogers, \& Harris, 
2006; Holmes, 2004; Mundava \& Chaudhuri, 2007; Song \& Cadman, 2013; Song-Turner, 2008). In her study of academic writing and plagiarism, Pecorari (2008) noted that it is possible that limited opportunities to practice citation skills or a lack of English proficiency may sometimes lead to plagiarism even though the student had no intention to deceive. Instead of assuming that every act of plagiarism is a moral problem, Robillard and Howard (2008) suggested that each incident be examined from the standpoint of the identities and social contexts of those involved.

Even if students are proficient in English, studies with international students in the United Kingdom revealed that knowing how to write in another language goes beyond understanding grammar to understanding how knowledge is constructed (Gow, 2014; Gu \& Brooks, 2008). Focusing solely on writing skills without a discussion of language terms and cultural views of knowledge may be inadequate for students to comprehend an institution's concept of academic honesty. In Holmes' (2004) research with Chinese students at a university in New Zealand, she observed that differing cultural views of knowledge, the failure of teachers to help students understand what constitutes plagiarism in their discipline, and the use of a language-learning strategy that involves students emulating the words of an expert may inadvertently lead to plagiarism.

Understanding English words does not mean one understands the concept behind the word. In an Asian Studies course developed for Chinese speakers at an Australian university, professors sought to meet the needs of the students by designing an interactive course which they conducted bilingually in English and Chinese (Song \& Cadman, 2013). As part of the course, the students and professors discussed research terms and clarified concepts. The professors found it necessary to demystify "often 'secret' terms associated with the Western academy" (p. 263) such as research, primary and secondary data, and logic. The students discussed their experiences with the various terms, engaged in activities, and reached a consensus on the meaning of the terms. The students were then given assignments to demonstrate their awareness and proficiency in the use of the terms.

Researchers at the University of Albany (Chen \&Van Ullen, 2011) designed and conducted two workshops for international students, one on the research process and another on plagiarism. Most of the study participants were graduate students. The researchers gave pre-tests and posttests in each workshop to discern students' understanding. The workshop post-tests showed a statistically significant increase in the students' understanding of both the research process and plagiarism. Because Asian students were the largest group of international students and composed more than $75 \%$ of the study participants, the researchers compared their scores with those of the non-Asian participants. They found no statistical difference 
between the scores of the two groups. Because of the emphasis in research in doctoral programs, the authors were surprised that there was also no statistical difference between the masters students' and the doctoral students' scores. The authors noted, however, that most of the doctoral students were in their first year in the United States and "were at the same level of academic experience" (p. 122) as the masters students.

As noted previously, training on plagiarism and academic honesty policies offered to all students differs from university to university and also differs based on whether one is an undergraduate or a graduate student (Jamieson, 2008; Pecorari, 2008). In their study, Voelker, Love, and Pentina (2012) found little difference between undergraduate and graduate students in the students' understanding of plagiarism. They concluded that many low-performing students may have heard about plagiarism and understand the consequences but "genuinely do not understand what plagiarism means" (p. 40). In the university where the current study was conducted, in order to register, all freshmen undergraduates and transfer students are required to have a perfect score in an online academic integrity tutorial. There is no similar requirement for graduate students though plagiarism and academic honesty are mentioned in graduate orientation. Howard (2008) noted that in the educational model where knowledge passes from the professor to the student, it may be assumed that graduate students already know the rules. Howard observed that for faculty, plagiarism among graduate students often "takes on intensified force" (p. 92) because faculty mentor graduate students, see them as future colleagues, and may collaborate or coauthor articles with them.

\section{RESEARCH METHOD}

For this study, the workshop format for sharing knowledge was chosen because previous research has indicated the efficacy of workshops in assisting international students to better understand their host university's expectations (Chen \& Van Ullen, 2011; Craig et al., 2010). Scenarios were used in the post-test to examine the participants' understanding of the concepts that were presented (Song \& Cadman, 2013). The quantitative data obtained from the workshops served as a starting point for the qualitative portion of the study. The research questions were: (a) Does an academic integrity workshop that is taught from a cultural perspective influence Asian graduate students understanding of a U.S. American university's concept of academic integrity and plagiarism? (b) How do Asian graduate students' cultural perception of knowledge influence their understanding of a U.S. American university's concept of academic integrity and plagiarism?

An explanatory sequential mixed methods research design was chosen in which the quantitative study of the workshop's effectiveness was 
to be followed by a qualitative case study investigating selected participants' academic experiences in their home and host cultures. A University Research Grant was obtained from the university site, approval was received from the Institutional Review Board, and a research team was assembled. After a thorough examination of the literature, the team developed workshop objectives with an expectation that the workshop would equip the participants to understand the university's perspective concerning:

- Academic dishonesty including plagiarism and self-plagiarism.

- The concept of common knowledge.

- Paraphrasing, including improper paraphrasing and patchwriting.

- Proper and improper citation practices.

- Acceptable research practices and practices that put one in danger of being academically dishonest.

- The consequences of committing plagiarism.

- The concept of intellectual property, including code of ethics, patents, copyrights, and trade secrets.

The research team prepared the workshop and a power point presentation that would meet the workshop objectives, entitling the workshop, "Making Good Decisions (MGD).”

The research team constructed a summative test to assess the workshop's effectiveness. Most of the questions were scenario-based and asked the respondent to identify whether or not the action in the scenario was allowable or would put the student at risk of being academically dishonest. Initially, 90 questions were developed, tested, and discussed. The final test was composed of 55 scenario-based questions and eight multiplechoice questions for a total of 63 questions. Pilot testing showed that the test required from 30 to 40 minutes to complete. The test was put into Qualtrics, an online survey site, for workshop participants to complete online following the workshop.

An invitation to participate was sent to the more than 200 Asian graduate students enrolled at the university through the International Education Office. The invitation offered each student a $\$ 25$ gift certificate to a local grocery store for his or her participation. Response was minimal. In further email communications, more details about the workshop were communicated, assuring confidentiality and focusing on the research team's desire to increase cross-cultural understanding. Investigations revealed that some students were confused about the research process and were concerned that findings might put them in a negative light. In spite of the small response, it was decided to continue the investigation as a basis for further studies.

The MGD workshop was offered three times and was conducted in the university library computer lab by the member of the research team with 
the most cross-cultural experience. A total of 19 Asian graduate students participated in the workshops though only 17 completed the post-test in the allotted 40-minute time following the workshop. It was decided that demographic data would not be requested because of the students' reluctance to engage in the research project and their fear of having responses traced to them. All 19 students responded to questions at the end of the post-test about their perception of the workshop's effectiveness in increasing their understanding of academic honesty, plagiarism, and intellectual property.

For the qualitative portion of the study, twelve of the MGD workshop participants were contacted and asked to participate. Ultimately, only three students agreed to be interviewed. None of the students with the lower scores agreed to be interviewed. The three participants, one male and two females, were from India, Bangladesh, and South Korea. The two females were in doctoral programs, one in the School of Education and the other in the School of Arts and Sciences and both had received their undergraduate and master's degrees in their home countries. The male was in a dual master's program in the Social Sciences and had completed his undergraduate degree in his home country. The three participants were interviewed using a semi-structured format, a data analysis procedure typical to basic qualitative study where researchers are interested in discovering the meaning that individuals ascribe to their realities (Merriam, 2009). The interviews for the three participants were audio recorded and were conducted by the research team member who conducted the MGD workshops. The recordings were transcribed, and the transcriptions were approved by the participants.

The interview transcripts were read several times and comments were divided into those comments that pertained to the participants' home countries and those that pertained to their experiences in the United States. The two groupings were divided into categories and further coded (Creswell, 2013) as themes emerged. It was decided, following approval from the Institutional Review Board, to move to a multi-phase research design. The purpose of the second phase was to obtain more data in order to answer the first research question concerning the workshop's effectiveness by asking volunteers from the general graduate student population to take the test without having the workshop. The Graduate School and various Graduate Student Association representatives advertised this opportunity for graduate students at the university. A $\$ 15$ gift card to a coffee shop was given to those who chose to participate. A convenience sample of 68 graduate students took the online test. One student stopped the test midway after missing several questions resulting in a total of 67 participants who completed the test. As the demographic questions were at the end of the test, it is not known if the student who stopped taking the test were an 
international student. Seven of the 67 participants self-identified as international students. Five of those seven were from Asian countries.

\section{Participants}

The Asian international graduate student population was not chosen because of an assumed difference between their responses and those of other international graduate students (Chen \& Van Ullen, 2011). Asians were the largest group of international graduate students at the research site and because the workshop was to be conducted from a cultural perspective, it was thought that choosing this population, even though varied, would reduce variables.

\section{RESULTS}

It is unfortunate that there were not enough participants to conduct the study as planned as an analysis of the test results suggested interesting trends that warrant further investigation. Participants' test scores were calculated on a possible 100 points. The lowest test score (63.5) was made by a student who did not participate in the MGD workshop but who took the test as part of the general graduate student population. This student self-identified as Asian but not as an international student. There were 1 Chinese, 3 Korean, and 1 student from Nepal who self-identified as international students for a total of 5 Asian students who took the test that was offered to all graduate students without benefit of the MGD workshop. The test mean of 88.7 for all of the graduate students who took the test without benefit of the MGD workshop was the same as that of the Asian graduate students who attended the MGD workshop. However, the mean score of the five Asian graduate students who took the test without benefit of the workshop was 80.3 with a range of 74.6 to 90.5 compared to a range of 77.7 to 100 for those Asian graduate students who took the MGD workshop. The only participant in all groups to correctly answer all of the test items was a student who attended the MGD workshop.

One portion of the test examined the participants' knowledge of acceptable paraphrasing. In this portion comprising 11 questions, participants were given a reference for an article. They were then given a one-sentence direct quotation from the article as well as a paraphrase of the sentence and were asked to identify whether the paraphrase were acceptable or if it put the writer at risk of committing plagiarism. Participants who did not take the workshop struggled more on this portion of the test than those students who took the workshop. Paraphrase examples from the test that participants said were acceptable but are not, are given below. The following is the APA reference given to the participants for the paraphrase questions. 
Barnard-Brak, L., Bagby, J. H., Jones, N., \& Sulak, T. (2011). Teaching post 9/11 student-veterans with symptoms of PTSD: The influence of faculty perceptions and self-efficacy. Journal of Vocational Rehabilitation, 35, 29-36. doi: 10.3233/JVR-2011.0551

Quotation \#1: "With large numbers of student veterans returning to higher education due to the reauthorization of the GI Bill, faculty and staff's ability to serve the needs of these students becomes a salient issue.”

Paraphrase \#1: With great numbers of student veterans returning to college due to the reauthorization of the GI Bill, professors' ability to serve the needs of these student veterans becomes an important issue (BarnardBrak, Bagby, Jones, \& Sulak, 2011).

Patchwriting is the process of substituting vocabulary or phrases for words in an original sentence, often leaving the structure of the original sentence intact. None of the workshop participants said that Paraphrase \#1, an example of patchwriting, was acceptable whereas $31 \%$ of those participants who did not take the workshop incorrectly said Paraphrase \#1 was acceptable.

Paraphrase \#2: Barnard-Brak, Bagby, Jones, and Sulak (2011) note that with the increasing student veteran population, faculty and staff's ability to serve the needs of these students becomes a salient issue.

From those taking the MGD workshop, 2 of the 17 participants, $12 \%$, incorrectly said Paraphrase \#2 was acceptable whereas 23 of the 67 students who only took the test, $34 \%$, incorrectly said Paraphrase \#2 was acceptable.

Quotation \#2: "We surveyed 596 faculty members as to their views of serving in the military, the United States' involvement in the Iraq/Afghanistan wars and perceptions of their ability or self-efficacy to address the special needs of combat veterans in the classroom."

Paraphrase \#3: Barnard-Brak, Bagby, Jones, and Sulak (2011) surveyed 596 faculty members as to their views of serving in the military, the United States' involvement in the Iraq/Afghanistan wars and perceptions of their ability or self-efficacy to address the special needs of combat veterans in the classroom.

Although Paraphrase \#3 is almost exactly the same as the quotation, two of the 17 workshop participants (12\%) and 20 of the 67 graduate 
students who only took the test (30\%) incorrectly said Paraphrase \#3 was acceptable and would not put the student in danger of committing plagiarism.

The MGD workshop participants used a 5-point Likert-type scale to respond to questions concerning how they perceived the MGD workshop. Sixty-three percent of the participants agreed or strongly agreed that their understanding of the issues surrounding academic integrity and plagiarism were greater following the workshop.

The three graduate students from India, Bangladesh, and South Korea who had participated in the MGD workshop agreed to be interviewed on condition of anonymity. In spite of the wide cultural differences between the three countries represented, the participants' responses (P1, P2, and P3) were surprisingly similar. Specific participant descriptions linking participants to their comments will not be given in order to preserve confidentiality. The following seven themes emerged from the interviews.

\section{Theme 1: Participants' home population's view of sharing knowledge.}

All of the participants spoke of the importance of sharing knowledge, whether it be sharing knowledge freely with family or others of the same social status or impressing others with ones' knowledge. In communal societies they noted that knowledge is to be shared, and it is not necessary to attribute knowledge to a specific individual. P3: "Knowledge is a much freer concept .... . If an old man dies with knowledge that he did not teach to someone else, it would be quite shameful."

Though this concept of knowledge may be the general public's view, students are expected to have specialized knowledge pertinent to their field. In educational systems where students may choose a profession when they begin high school, students often study only topics relevant to that field. According to one participant, students accustomed to specialized knowledge may have difficulty understanding the goals of a liberal arts education in the United States and may turn to plagiarism when required to take courses that do not appear to contribute to the student's main career goals and in which the student has little background.

\section{Theme 2: Participant's home population's view of copyright.}

All of the participants conceded that while there were copyright laws in their countries, they were difficult, if not impossible, to enforce.

P3: "The concept of selling books doesn't arise. ... [my people] are quite voracious readers but they have no problem photocopying books.”

In the more impoverished countries, a lack of resources drove students and faculty alike to find materials wherever they could. 
Theme 3: Students' higher education experiences in their home countries and attitudes toward academic honesty and plagiarism.

The participants painted a picture of an educational system in their homelands where teachers and older people are respected for their knowledge, and students are expected to be respectful receivers of that knowledge.

P1: "The teacher being authoritative and the student being deferential is still quite strongly in place. . . .It has become a little more relaxed over the last 10 or 15 years."

P2: "It is hard to get close . . . the teacher and student. They are different.”

P3: "There are countless sayings, old proverbs like, "Worship your teacher." There is always the concept that the teacher is the smarter person because they are the ones doing the teaching. Nothing can change that."

None of the three participants had been asked to do research until they attended university. With limited access to academic databases or outdated library resources, faculty were often lenient.

P1: "Definitely they [students] will sometimes take a paper from somewhere whether it's online or a book or get someone else to write it or take an old paper from a sibling or a friend and they will pass it off. The consequences will really vary. A lot of teachers don't even check to see if it were plagiarized. And for those who do, I don't think that anyone really turns a blind eye entirely, but the severity of the punishment varies."

P2: "As a freshman, I would always copy and paste, copy and paste. In college, the professors did not check. In graduate school, however, a professor said we could not do that."

Theme 4: Participants' orientation experiences concerning academic honesty and plagiarism issues prior to and upon arrival at a U. S. American university.

The participants' experiences varied concerning their orientation to academic honesty issues in their host countries. The South Korean participant talked about the prevalence of guidebooks that discussed the issue, guidebooks which prospective students and their parents habitually read. The other participants received no orientation but "picked up" information about academic honesty once they arrived in the United States if their professors happened to discuss the issue when going over the syllabus. One participant learned about plagiarism "the hard way."

Theme 5: Participants' perceptions of fellow international students' attitudes toward the emphasis North American universities place upon academic honesty issues. 
Two of the participants mentioned the students' frustration, feeling the emphasis that North American universities placed on the issue was extreme. One participant's frustration arose from believing there was little new knowledge, especially in the area of textual criticism. Feeling that the responsibility of researching others' work, just to be sure that what the student was writing and thought to be original had not been written before, was an oppressive burden. The student feared that without such research, an expert in the field who was familiar with others' writings may believe that the student had plagiarized another's ideas, even if the student's work were original.

Another participant believed that plagiarism was not an issue of unfamiliarity with English but was more unfamiliarity with liberal arts curriculum where international students in a particular study track who had studied biology, for example, since high school suddenly found themselves thrust in a U.S. history course where they had no background and little interest. Plagiarism often made sense to them in those instances where all they cared about was getting through the course as quickly as possible so they could spend their time in their chosen field.

Theme 6: Participants' suggestions of how they would approach the topic of plagiarism if orienting international students from their home countries.

All of the participants said they would stress the consequences of committing plagiarism as well as emphasizing the hard work involved in learning the academic skills so students would not be tempted to plagiarize. They also mentioned the importance of developing an academic community.

P1: "I would probably also talk a little bit about pride in one's work, so that I'm not approaching it, right from the beginning, with negativity but also telling students why, in general, it's just nice if you've done your own work and not just depended on someone else. Especially because a lot of them are spending money to be here, they're trying to get an education, so why not get the full experience and have something they can call their own?"

P3: "Explain the concept of stealing and compare it to real stealing - and this is real stealing, in the academic culture, that is universal, I think. But compare it to what is a tangible thievery in their own culture ... . Yes, knowledge is free, and yes, anyone could have spent the time - maybe - and gotten it, but this is years of study so it belongs to someone. So, if you take it, you've stolen it, unless you give them credit.”

Theme 7: Participants' beliefs concerning what administration in North American institutions of higher education need to know about the topic of international students and plagiarism. 
The participants agreed that it was necessary to have plagiarism workshops and orientation for newcomers, especially graduate students who did not do their undergraduate work in a North American institution. Their suggestions included not assuming that plagiarism is a moral or ethical issue but more of an issue of ascribing different cultural meaning to the practice of using others' ideas. When asked what university administration needed to know, one participant spoke candidly.

P1: "I think they definitely need to know that ... this is how it is in other countries .... it really almost has no importance in a lot of other countries. “

The participant continued by saying that in countries where copyright laws are difficult to enforce, academic authors "put books together" to help the students without an expectation of royalties.

P1: In some ways it [putting books together] is good, and in some ways it is bad . . . it's like it's good that people would now only put a book together because of the good it would do for students who are going to use it. That is also, I think, kind of holding some people back from doing any hard work because they know, there isn't going to be a lot of money in this.”

\section{DISCUSSION AND CONCLUSIONS}

The purpose of this study was to assess the influence of a workshop, taught from a cultural perspective, on Asian international graduate students' perceptions of a U. S. American university's concept of plagiarism and academic honesty and to learn about the participants' concepts of textual practices in their home countries. Though there were not enough participants to conduct the study as initially envisioned, moving to two phases and examining the process provided insight into the dynamics involved when addressing academic honesty issues cross-culturally.

Many Asian graduate students were reluctant to participate in the study. It is not known whether their reluctance is indicative of sensitivity to the topic, a lack of familiarity with the research process, or simply the result of busy schedules typical of graduate students. Research in the area of survey nonresponse suggests that in cultures where the communication style includes understanding the context of a message, people may look for hidden motives if the interviewer is not a member of the in-group (Johnson, O’Rourke, Burris, \& Owens, 2002). In one study in Hong Kong, interviewers used focus groups when interviewing students because students were "usually scared” when interviewed individually (Kwong, Ng, Kai-Pan, \& Wong, 2010, p. 344).

The first research question was: Does an academic integrity workshop that is taught from a cultural perspective influence Asian graduate 
students understanding of a U.S. American university's concept of academic integrity and plagiarism? In spite of a reluctance to participate, 63\% of those students who took the workshop agreed or strongly agreed that their understanding of plagiarism and academic honesty were greater following the workshop. Sixty-eight percent stated that they had a greater understanding of paraphrasing. Participants from the qualitative portion of the study reported limited orientation concerning plagiarism before they left their home countries with one learning about the topic "the hard way" following arrival. Though these results cannot be generalized to the larger population of international graduate students, the participants' experiences illustrate the danger of assuming incoming international graduate students understand their host university's expectations when it comes to academic dishonesty and plagiarism.

Research has shown that international students studying in a foreign language need practice in knowing how to paraphrase correctly (Liao \& Tseng, 2010). Because the test was offered to graduate students who did not take the workshop, unforeseen results revealed confusion in the general graduate student population concerning acceptable paraphrasing practices. It may be beneficial for universities to provide all graduate students with information on correct paraphrasing, especially concerning the unacceptability of patchwriting.

The second research question was: How do Asian graduate students' cultural perception of knowledge influence their understanding of a U.S. American university's concept of academic integrity and plagiarism? In the qualitative portion of the study, though there are distinct differences in how the three Asian cultures represented view knowledge, the students from these cultures all agreed that in their home cultures, knowledge is seen as something that needs to be shared. They described people in their countries as sometimes being more interested in obtaining knowledge than worrying about respecting others' supposed rights of ownership. They noted the "extreme" views they found in the U. S. where it sometimes appeared as if university leadership were more interested in catching perpetrators than in offering training. This finding agrees with that of Awdry and Sarre (2013) when they noted that "tutors should focus less on the detection and punishment of plagiarism and more on the value of students completing their own work and valuing their own integrity” (p. 43). University leadership needs to be sensitive to this perception by showing their willingness to provide training on the academic literacy necessary to succeed in their environment (Song \& Cadman, 2013).

The primary limitation of this study was the small participant sample. With an insufficient number of willing participants, the results of this study cannot be generalized to larger Asian international graduate student populations. Also, all of the participants were drawn from the same 
research university in the Southwest of the United States. Participants in other academic settings may have responded differently.

\section{IMPLICATIONS}

With students in higher education becoming more mobile, there is an increasing need for better intercultural communication between students and university faculty or staff, especially on topics such as academic integrity and plagiarism which are often influenced by cultural values. People's views of whether knowledge should be shared or can be owned may influence their attitudes toward these topics. Making value judgments without proper orientation to cultural differences discourages students and faculty alike and can lead to adversarial positions. International students can benefit from training that discusses academic honesty issues from a cultural perspective as they are led to understand and adhere to their host university's policies.

There may be an assumption among higher education leadership that all students who enter graduate programs already understand an institution's expectations when it comes to academic honesty and plagiarism. This assumption may be false, however, especially when students completed their undergraduate education at other universities. Institutions of higher education must provide adequate orientation programs to all incoming graduate students, domestic students as well as international students, especially if there is confusion about such issues as acceptable paraphrasing practices.

In these days of continuing internationalization of higher education, exploring the cultural elements of academic honesty and meeting the need of the entire graduate student population to develop paraphrasing skills will also help international students understand expectations and will assist universities to address academic honesty concerns on campus.

Research is needed to study the issues that emerged in this study. Research might reveal how university faculty and administration can be more culturally sensitive in addressing academic honesty concerns with international students. If international students are reluctant to address the topic, they may not be taking advantage of an institution's efforts to help them. Research is also needed to explore whether providing workshops that address academic integrity issues from a cultural perspective are more effective than general workshops that discuss the mechanics of plagiarism.

\section{REFERENCES}

Abasi, A. R., Akbari, N., \& Graves, B. (2006). Discourse appropriation, construction of identities, and the complex issue of plagiarism: ESL students writing in graduate school. Journal of Second Language Writing, 15(2), 102-117. doi: 10.1016/j.jslw.2006.05.001 
Abasi, A. R., \& Graves, B. (2008). Academic literacy and plagiarism: conversations with international graduate students and disciplinary professors. Journal of English for Academic Purposes, 7, 221-233. doi: 10.1016/j.jeap.2008.10.010

Amsberry, D. (2010a). Deconstructing plagiarism: International students and textual borrowing practices. The Reference Librarian, 51, 31-44. doi: $10.1080 / 02763870903362183$

Amsberry, D. (2010b). Plagiarism and the nontraditional student: Challenges and perspectives. In V. B. Cvetkovic \& K. E. Anderson (Eds.), Stop plagiarism: A guide to understanding and prevention (pp. 107-116). New York, NY: Neal-Schuman Publishers.

Awdry, R., \& Sarre, R. (2013). An investigation into plagiarism motivations and prevention techniques: Can they be appropriately aligned? International Journal for Educational Integrity, 9(2), 35-49.

Chen, Y.-H., \& Van Ullen, M. K. (2011). Helping international students succeed academically through research process and plagiarism workshops. College and Research Libraries, 72(3), 209-235.

Craig, P. A., Federici, E., \& Buehler, M. A. (2010). Instructing students in academic integrity. Journal of College Science Teaching, 40(2), 50-55.

Creswell, J. W. (2013). Qualitative inquiry research design: Choosing among five approaches (3rd ed.). Thousand Oaks, CA: Sage.

Day, K. (2008). Time is not on our side: Plagiarism and workload in the community college. In R. M. Howard \& A. E. Robillard (Eds.), Pluralizing plagiarism (pp. 43-61). Portsmouth, NH: Boynton/Cook Publishers.

Duff, A. H., Rogers, D. P., \& Harris, M.D. (2006). International engineering students - avoiding plagiarism through understanding the Western academic context of scholarship. European Journal of Engineering Education, 31(6), 673-681. doi: 10.1080/03043790600911753

Gallant, T. B. (2008). Academic integrity in the twenty-first century: A teaching and learning imperative. San Francisco, CA: Wiley Bass.

Gow, S. (2014). A cultural bridge for academic integrity? Mainland Chinese master's graduates of UK institutions returning to China. International Journal for Educational Integrity, 10, 70-83.

$\mathrm{Gu}$, Q. (2010). Variations in beliefs and practices: Teaching English in crosscultural contexts. Language and Intercultural Communication, 10, 32-53. doi: 10.1080/14708470903377357

Gu, Q., \& Brooks, J. (2008). Beyond the accusation of plagiarism. Science Direct System, 36, 337-352. doi: 10.1016/j.system.2008.01.004

Holmes, P. (2004). Negotiating differences in learning and intercultural communication - Ethnic Chinese students in a New Zealand university. Business Communication Quarterly, 67(3), 294-307. doi: 1080569904268141

Howard, R. M. (2008). Plagiarizing (from) graduate students. In R. M. Howard \& A. E. Robillard (Eds.), Pluralizing plagiarism (pp. 92-100). Portsmouth, NH: Boynton/Cook Publishers.

Hu, G., \& Lei, J. (2012). Investigating Chinese university students’ knowledge of and attitudes toward plagiarism from an integrated perspective. Language learning, 62(3), 813-850. doi: 10.1111/j.1467-9922.2011.00650.x 
Institute of International Education (2015). Open doors report 2014 fast facts. Retrieved from http://www.iie.org/opendoors

Jamieson, S. (2008). One size does not fit all: Plagiarism across the curriculum. In R. M. Howard \& A. E. Robillard (Eds.), Pluralizing plagiarism (pp. 7791). Portsmouth, NH: Boynton/Cook Publishers.

Johnson, T. P., O’Rourke, D., Burris, J., \& Owens, L. (2002). Culture and survey nonresponse. In Groves, R. M., Dillman, D. A., Eltinge, J. L. \& Litle, R. J. (Eds.), Survey nonresponse (55-70). New York, NY: Wiley.

Kim, H. Y. (2011). International graduate students’ difficulties: Graduate classes as a community of practices. Teaching in Higher Education, 16, 281-292. doi: 10.1080/13562517.2010.524922

Kwong, T., Ng, H.-M., M. Kai-Pan, \& Wong, E. (2010). Students’ and faculty’s perception of academic integrity in Hong Kong. Campus-Wide Information Systems, 27, 341-355.

Leki, I. (2006). Negotiating socioacademic relations: English learners’ reception by and reaction to college faculty. Journal of English for Academic Purposes, 5, 136-152.

Lewin, T. (2012, February 5). Taking more seats on campus, foreigners also pay the freight. The New York Times, pp. 1, 21.

Liao, M.-T., \& Tseng, C.-Y. (2010). Students' behaviors and views of paraphrasing and inappropriate textual borrowing in an EFL academic setting. Journal of Pan-Pacific Association of Applied Linguistics, 14, 187-211.

Lipson, C. (2008). Succeeding as an international student in the United States and Canada. Chicago: The University of Chicago Press.

Merriam, S. B. (2009). Qualitative research: A guide to design and implementation. San Francisco, CA: Jossey-Bass.

Mundava, M., \& Chaudhuri, J. (2007). Understanding Plagiarism. College \& Research Libraries News, 68, 170-173. Retrieved from http://crln.acrl.org/content/68/3/170.full.pdf+html

OECD. (2014). Education at a glance 2014: OECD indicators. OECD Publishing. Retrieved from http://dx.doi.org/10.1787/eag-2014-en

Pecorari, D. (2008). Academic writing and plagiarism: A linguistic analysis. New York, NY: Continuum.

Pfeuffer-Scherer, D. (2010). Plagiarism: University reaction and subsequent action. In V. B. Cvetkovic \& K. E. Anderson (Eds.), Stop plagiarism: A guide to understanding and prevention (pp. 95-106). New York, NY: NealSchuman Publishers.

Plagiarism. (2016). In Oxford Dictionaries online. Retrieved from http://www.oxforddictionaries.com/us/definition/american_english/plagiari $\mathrm{sm}$

Plagiarism. (2015). In Merriam-Webster dictionary online. Retrieved from http://www.merriam-webster.com/dictionary/plagiarism

Ramzan, M., Munir, M. A., Siddique, N., \& Asif, M. (2012). Awareness about plagiarism amongst university students in Pakistan. Higher Education, 64, 73-84. doi: 10.1007/s10734-011-9481-4

Robillard, A. E., \& R. M. Howard (2008). Introduction: Plagiarisms. In R. M. Howard \& A. E. Robillard (Eds.), Pluralizing plagiarism (pp. 1-7). Portsmouth, NH: Boynton/Cook Publishers. 
Sato, T., \& Hodge, S. R. (2009). Asian international doctoral students' experiences at two American universities: Assimilation, accommodation, and resistance. Journal of Diversity in Higher Education, 2, 136-148. doi: $10.1037 / \mathrm{a} 0015912$

Shi, L. (2006). Cultural backgrounds and textual appropriation. Language Awareness, 15, 264-282. doi: 0965-8416/06/04 0264-19

Song, X., \& Cadman, K. (2013). Education with(out) distinction: beyond graduate attributes for Chinese international students. Higher Education Research \& Development, 32, 258-271. doi: 1080/07294360.2012.673573

Song-Turner, H. (2008). Plagiarism: Academic dishonesty or 'blind spot' of multicultural education? Australian Universities’ Review, 50(2), 38-50.

Voelker, T. A., Love, L. G., \& Pentina, I. (2012). Plagiarism: What don't they know? Journal of Education for Business, 87, 36-41. doi: 10.1080/08832323.2011.552536

LANETTE W. THOMPSON, PhD, is the Assistant Director for Student Life Assessment and Planning at Baylor University. Her research interests include assessment, adult learning, and intercultural communication. Email: lanette_thompson@baylor.edu

JANET H. BAGBY, $\mathrm{PhD}$, is a Senior Lecturer for the Educational Psychology Department at Baylor University. Besides teaching, she mentors students and researches non-traditional students' effective transitions to academia. Email: janet_bagby@baylor.edu

TRACEY N. SULAK, PhD, is a Clinical Assistant Professor in educational psychology at Baylor University. Her research and teaching interests include school climate and teacher education. Email: Tracey_Sulak@baylor.edu

JANET SHEETS, MLS, is an Associate Professor Emerita from the Baylor University Libraries where she was the Liaison Librarian for the School of Education. Email: Janet_Sheets@baylor.edu

TONYA M. TREPINSKI, PhD, is an adjunct professor at Texas A \& M International University. She teaches special education and behavior analysis courses. She also works as a college adviser at a private school. Email: tonya.trepinski@tamiu.edu

Manuscript submitted: August 11, 2015 Manuscript revised: January 24, 2016 Accepted for publication: May 5, 2016 